\title{
APPLICATION OF SAFETY INSPECTIONS FOR EVALUATION OF TWO - LANE REGIONAL ROADS IN POLAND
}

\author{
S. CAFISO ${ }^{1}$, M. KIEĆ ${ }^{2}$, M. MILAZZO ${ }^{3}$, G. PAPPALARDO ${ }^{4}$, F. TROVATO ${ }^{5}$
}

In the paper methods for conducting Road Safety Inspections (SIs) in Italy and Poland are described and compared. The goal of the study is to improve the quality and efficiency of the safety inspections of road network by using low cost equipment (GPS, Tablet, Camera) and specific software. Particular attention was paid to the need for proper calibration of factors, causing traffic safety hazard associated with road infrastructure. The model developed according to the Italian procedures was adapted to comply with the checklists and evaluation criteria of the Polish guidelines. Overall, a good agreement between the two approaches was identified, however some modification was required to include new safety issues, characteristic for the Polish network for safety inspection of two lane rural roads. To test the applicability about $100 \mathrm{~km}$ of regional two lane roads in Poland were inspected with Polish and Italian procedures.

Keywords: road safety, safety inspection, road infrastructure, two lane rural roads,

\section{INTRODUCTION}

The period of intensive realization of road investments causes the evaluation of the operation of the existing road network and even the new investments to seemingly become less important. However, in the old EC member states like Italy, operation and maintenance of the existing network and continuous improvement of traffic safety are very important. The European Directive 2008/96/CE [1] requires the member states to establish and implement procedures oriented on improvement of the existing network, namely: road safety impact assessments (i.e. evaluation of the projects of new invest-

1 Corresponding author, Department of Civil and Environmental Engineering, School of Engineering, University of Catania, dcafiso@dica.unict.it

2 Department of Highway and Traffic Engineering, Cracow University of Technology, mkiec@pk.edu.pl

3 Department of Civil and Environmental Engineering, School of Engineering, University of Catania, milazzomarco60@gmail.com

4 Department of Civil and Environmental Engineering, School of Engineering, University of Catania, giusy.pap@dica.unict.it

5 Department of Civil and Environmental Engineering, School of Engineering, University of Catania, fabriziatrovato@gmail.com 
ments regarding efficiency of road safety improvements), road safety audits (evaluation of road designs regarding traffic safety), the management of road network safety, and Road Safety Inspections (SIs; the management and security of existing roads in order to identify the road safety related features and prevent accidents).

Poland has already implemented road safety audit and road safety impact assessments and is preparing implementation of the in the SIs. Road Safety Inspections are an effective tool for the management and maintenance of safety on existing roads in order to identify those elements with high risk of accident for the user.

The aim of the study presented in the paper is to implement the Italian experience in conducting the SIs in Poland, and also to improve the efficiency of the periodic inspections by using low cost equipment.

In the aforementioned Directive, great emphasis is given to road SIs as an effective tool for the safety management of existing roads stating: "Once road sections with a high accident concentration have been treated and remedial measures have been taken, safety inspections as a preventive measure should assume a more important role. Regular inspections are an essential tool for preventing possible dangers for all road users, including vulnerable users". Within the Article 6 of the "Safety Inspections" it is also recognized that member states shall carry out safety inspections on existing roads in order to identify the features related to road safety and to prevent collisions and accidents.

The inspections should be performed periodically and by a competent entity. Member states are also encouraged to apply this directive on other national roads, which are not part of the Trans - European Road Network (TEN). Two-lane rural roads -investigated in this study - are the main part of the national and regional road network in Poland, used by through and local traffic. The use of SIs is one of the measures to improve traffic safety in Europe associated with the assessment of the accident risk on the existing elements of road infrastructure. SIs can be a source of information needed to prioritize treatments in road sections which produce the highest accident reduction and/or the highest safety' benefit-cost ratio. Unfortunately, guidelines for carrying out road safety inspections (Budzyński et al. [2]), implemented in Poland by GDDKiA in 2014, do not allow quantification of the accident risk basing on the conducted SIs. Such a possibility is introduced in a method developed in Italy and described in "Identification of Hazard Locations and Ranking of Measures to Improve Safety on Local Rural Roads" (IASP) (Cafiso et al. [3]), in conjunction with Risk Index (RI) (Cafiso et al. [4]) used to predict frequency and severity of accidents when using SIs. Therefore, the applicability of the IASP method, allowing quantification of the accident risk in Polish conditions, is described in the paper. One of the SIs elements is the assessment of the risk associated with road infrastructure. Because of different scales in the risk assessment in both methods (categories 3 and 4 are distinguished for the Italian and Polish methods, respectively) the calibration of scores in the Polish method to IASP, should be performed. 
In Europe road accidents are one of the main causes of death, with more than 120 000 deaths per year (European Commission [5]). This phenomenon is common in Europe, especially in the most of the Western countries (over a million deaths per year are recorded on roads all over the world).

Due to the technological progress which followed the introduction of crash tests, and to the slow but gradual introduction of safety devices, such as seat belts, the number of traffic fatalities has stopped growing in the EC countries around the beginning of the seventies, despite the fact that the number of cars in circulation and of accidents continues to rise.

It is interesting to compare Italian and Polish crash data. Figure 1 shows similar trends in time, but a higher number of accidents in Italy against a similar number of fatalities in both countries in the period from 2000 to 2012. These figures indicate lower frequency of accidents but their higher severity in Poland.
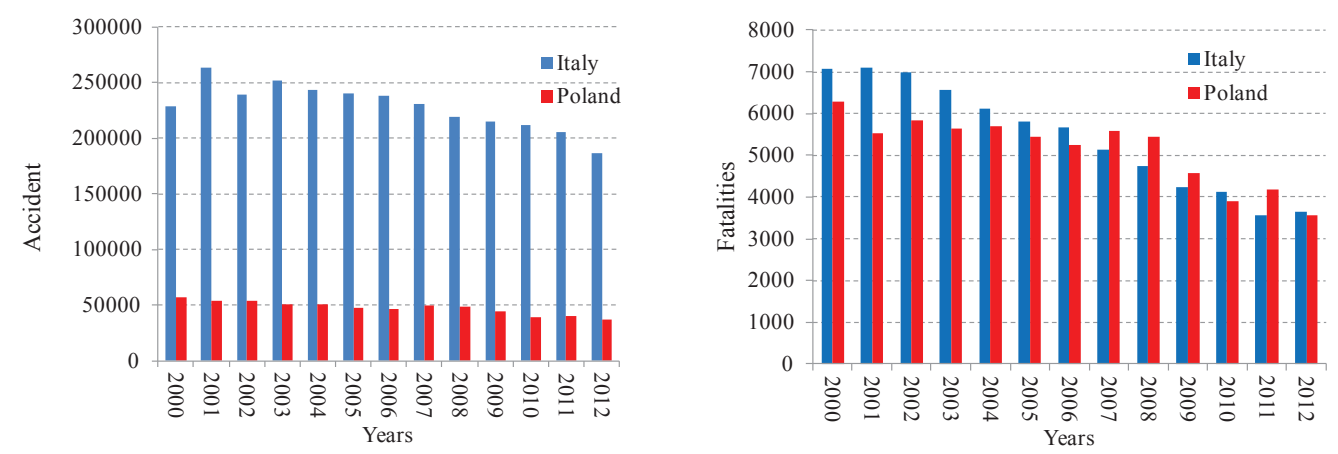

Fig. 1. Accident and fatalities in Italy and Poland $(2000-2012)$

In the lack of vehicle per $\mathrm{km}$ travel data, a comparison using as exposure factors $\mathrm{km}$ of roads, number of vehicles and inhabitants can be carried out. Table 1 shows such data for both countries and Figure 2 shows the resulting crash ratios.

Table 1

Data used in analyses of crash ratios.

\begin{tabular}{|c|c|c|c|}
\hline & Inhabitants & Vehicles & Roads length \\
\hline ITALY & $60,762 \mathrm{mln}$ & $51,218 \mathrm{mln}$ & $190372 \mathrm{~km}$ \\
\hline POLAND & $38,486 \mathrm{mln}$ & $23,037 \mathrm{mln}$ & $406979 \mathrm{~km}$ \\
\hline
\end{tabular}

Figure 2 presents values of fatalities per km, clearly indicating that these are higher in Italy than in Poland. Mortality crash ratios i.e. number of fatalities per 1000 vehicles or $1 \mathrm{mln}$ inhabitants are higher in Poland. This may suggest that in Italy there is a higher 
frequency of accidents which are not so serious, while in Poland there are fewer accidents, but these accidents are more severe than those recorded in Italy.

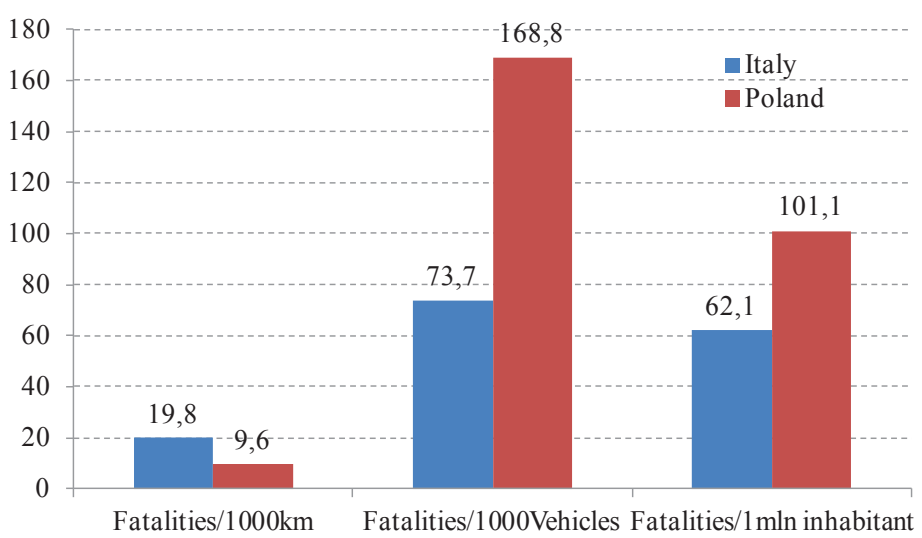

Fig. 2. Comparison between Italy and Poland in terms of fatalities $/ \mathrm{km}$ and fatalities/vehicle (2010 - 2012 mean value)

Even though there are differences regarding accident history between Italy and Poland, a similarity from geometrical and structural characteristics of the roads has emerged in both countries. According to DM 05/11/2001 [6] the two Italian two-lane rural roads F1 and F2 are similar to the regional roads in Poland, in particular to roads: $\mathrm{G}$ class (major roads) and $\mathrm{Z}$ class (collector distributor roads taking into account minimum geometrical characteristics. Although general speed limits are the same in both countries, the operating speed in Poland is higher than Italy.

A peculiar feature of regional roads in Poland, is the existence of built-up areas that are extended along these roads. Because the procedure to be applied was calibrated in Italy only for rural roads, road segments selected for testing the procedure have been situated exclusively in rural environment, with sections that had a minimum length of $410 \mathrm{~m}$ and a maximum length of $5 \mathrm{~km}$ of a continuous analysis.

In order to describe a few separate problems this paper is divided into 3 main sections presenting:

- IASP procedure for SIs,

- hardware and software tools for SIs conducted in field,

- implementation of IASP procedure within Polish guidelines for the SIs.

\section{BACKGROUND OF SIs}

A SIs is a formal examination of an existing road, in which an independent, qualified team reports accident risk potential and safety performance. Safety inspections are rec- 
ognized as an effective tool for identifying potential risks and are becoming an accepted practice in many agencies around the world. SIs are considered a part of the network safety management in The European Directive 2008/96/CE.

Depending on the complexity of the work, an inspection may be done by a single inspector or by a group of inspectors. Members of the group should be "independent", i.e. not part of the team that designed and built the road or maintains the road. They should have a very good, specialised and in-depth knowledge of the region, as well as an understanding of potential countermeasures and what is required for their implementation.

There are four steps in the SIs process:

- step 1: preparatory work in the office,

- step 2: on site field study,

- step 3: SIs report,

- step 4: introduction of remedial measures and follow up.

For a reliable inspection, observations should be made both from the car and on foot where needed. The road should be driven a number of times if possible and photographs of specific issues taken. During the inspection checklists, including lists of potential problems can be used and completed. Different checklists are required and the process can involve small sections of the road with repeated checklists, or several runs along the whole road using a single checklist. The chosen length depends on the complexity of the road. The checklists are quite detailed and consequently there should be a systematic collection of the deficiencies that were found.

The SIs report should consist of:

- an introduction (include details of the road or section of road being inspected and the composition of the inspection team, date, times and conditions at the time of the inspection),

- part A with data obtained during the preparatory work in the office and a description of the activities undertaken,

- part B describes the shortcomings or deficiencies which were found and an assessment of these deficiencies.

- part C should contain proposals for countermeasures, from short to long term.

Due to subjective nature of the process, inconsistencies may arise and limit inspections' effectiveness, but the research presented in the paper shows that well-defined operative procedures and methodologies for identifying the safety problems can improve both the effectiveness and the reliability of the safety inspections.

\subsection{IASP PROCEDURE}

The procedure is based in the IASP project (Cafiso et al. [3]), funded by European Commission (DG TREN) and Province of Catania (Italy) with the scientific coordination and operative support of the University of Catania. As part of the project, SIs procedures, which address rural two-lane highways, have been defined. Although many SIs proce- 
dures already exist, the IASP procedures present some innovative elements and, above all, they are very operational in nature.

The IASP SIs can inspect about $30 \mathrm{~km}$ of road daily. At least three operators are needed: the driver, the inspector in the front seat and the inspector in the back seat. Recommended equipment includes GPS receiver, a digital video camera and checklists. The road is ran in both directions at a very low speed (about $30 \mathrm{~km} / \mathrm{h}$ ).

Checklists are aimed at ensuring that important safety problems are not overlooked. Checklists are prompt and cannot substitute knowledge and experience of an inspector, i.e. checklists are auxiliary measures for safety engineering experience and judgment. IASP checklists are very concise (Cafiso et al. [7]), since they relate only to the main safety features which are usually present along two lane rural roads. Moreover, only features which are easily detectable during inspections have been included. Features which concern horizontal and vertical alignment (geometric alignment, design consistency, etc.) are not considered, since in the IASP safety analysis of alignment is performed as a separate quantitative procedure (road safety audit).

Checklists must be filled in both directions. Front seat and back seat inspectors, which have different views of the road, complete different checklists by filling the boxes with a step of $200 \mathrm{~m}(24 \mathrm{~s}$ at $30 \mathrm{~km} / \mathrm{h})$. In order to simplify the inspectors' task, any checklist is split in two parts: part A has to be completed on site, part B can be completed both on site and during the video examination performed in the office. Safety issues are ranked as:

- high level problem (rank 2),

- low level problem (rank 1),

- no problem (rank 0).

Ranking of safety issues can be used both as an aid for the prioritization of the safety measures and as an aid to road agencies in measuring the effectiveness over time of their safety improvement programs. After the preliminary inspection, the team analyses videos in the office and (if was not done on site) complete part B of the checklists. Checklists are completed in both directions referring in particular to the right side. By brainstorming among the team members checklist results are examined and the final version of the checklists is edited.

The IASP manual (Cafiso et al. [3]) suggests for each problem the recommendation typologies. Recommendations are engineering solutions to the reported problems. They indicate the type of measures, without specifying detailed technical issues.

Problems and recommendations are disaggregated in order to highlight the safety issues of each road feature, but road safety improvement requires an integrated approach where interaction among different measures must be taken into account.

As a final result of the meeting, a preliminary report describing general problems and recommendations is edited. Moreover, some sites requiring specific inspection (site visits) might be identified. 


\subsection{Hardware AND SOFTWARE TOOLS FOR ON-SITE INSPECTION}

In the IASP procedure the inspectors observe and evaluate road conditions, filling two different checklists. This task requires relevant expertise and skills of the inspectors. The innovative system developed by the University of Catania (Cafiso et al. [8]) and presented in this paper, frees the operator from the concern to link the position in the road segment to the checklist to be filled. The inspectors fill the checklists touching the screen of the tablet connected via Bluetooth to the GPS. In this way data is collected easily, stored and linked to the road segment where it was registered and synchronized with the video records.

The system has the objective to simplify the operator's work but opens up a whole set of issues which should be solved by the software without user's concern:

- allows easy data insertion/registration;

- links inspection data with unique road section travelling the route in both directions;

- stores all information to allow the post-inspection review.

In order to get an easy and low-cost solution, it was decided to create an Android application. By means of an easy-to-use interface the application allows the user to insert inspection data for each section of the road using his/her own tablet.

To improve accuracy in vehicle positioning, an external GPS receiver can be connected with the Android application running on the tablet. Finally, to associate also images of the road space, frames recorded by a video-camera installed on the vehicle can be geo-referenced and linked to the inspection data through a system of synchronization based on the GPS UTC time used as a metronome for all devices. The architecture and organization of the system is shown in Figure 3.

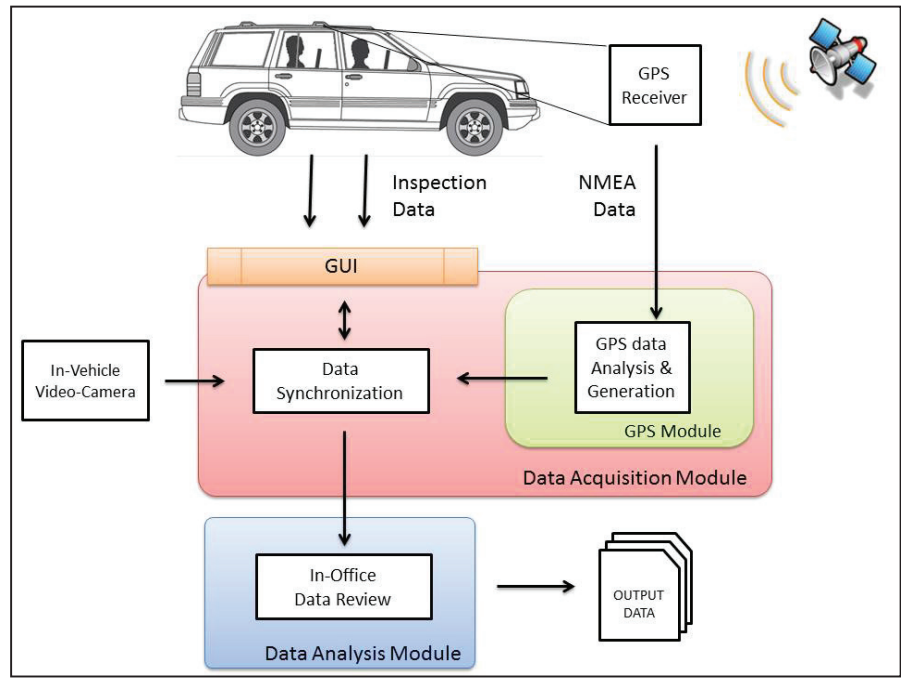

Fig. 3. Architecture and organization of the system 
If the GPS module is the "heart" of the system, the Data Acquisition Module is the "brain". This module uses data from GPS to support the inspector task via the Graphic User Interface (GUI) (Figure 4). The most important part of the in-field inspection is assessment of the safety issues and completing the checklist (Figure 4) for each road section of a fixed length, which compose the road segment under investigation.

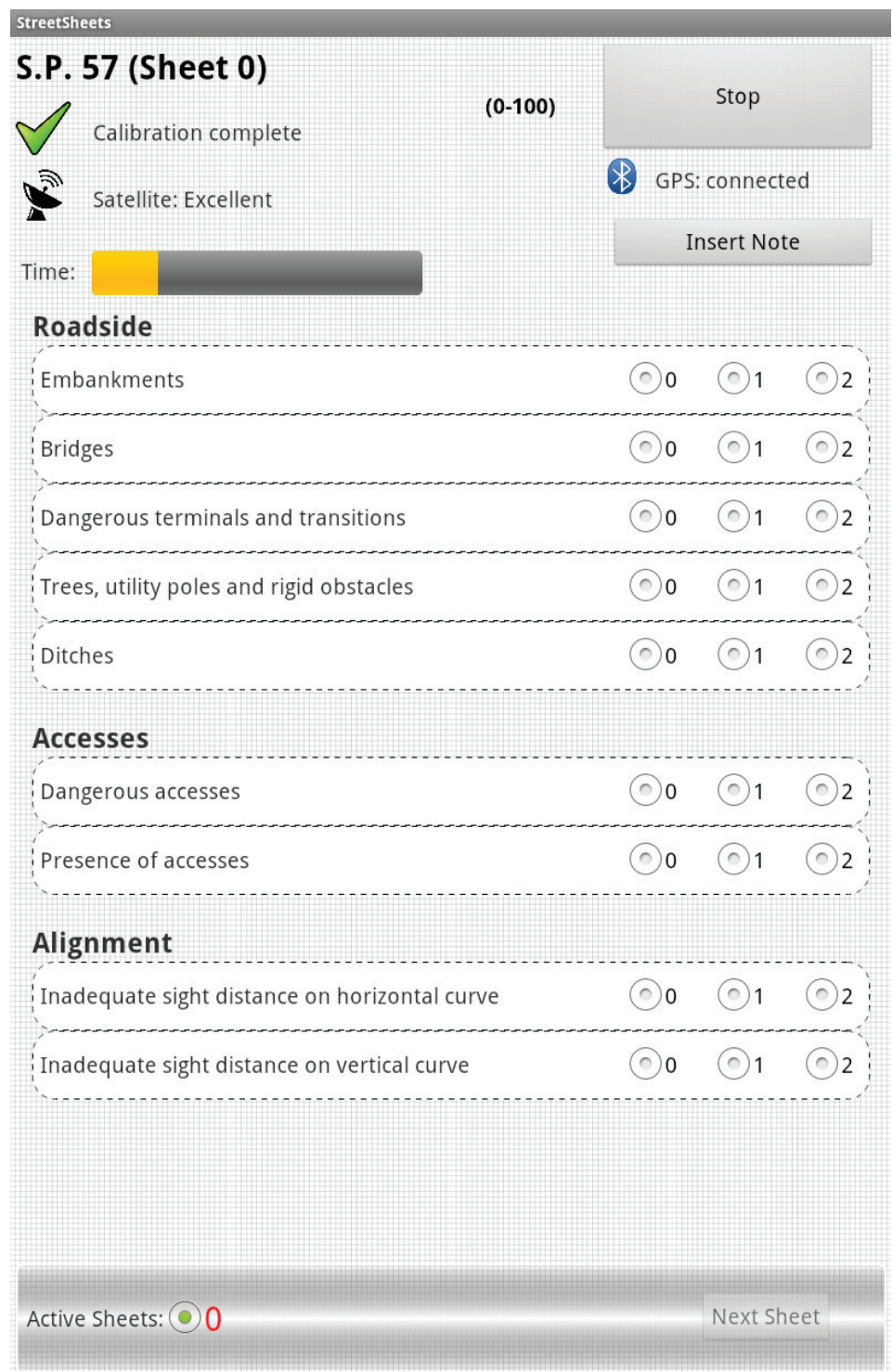

Fig. 4. GUI of the application 
For each inspection two checklist forms are available: one for the operator in the front seat and one for the operator in the rear one. The checklist form may be modified before the inspection because it is saved in the form of XML file which can be edited at any time.

If the inspection is carried out for a two-lane road, after the forward path inspection, the operator must begin a return path inspection in the opposite direction and the system helps to find the starting point of the return path. Once the acquisition procedure is concluded in both directions, the application merges the data obtained in the forward path to data obtained in the return path.

At the end of the infield inspection, the Data Acquisition Module exports all data in the form of text files that can be read and processed by the Data Analysis Module.

The Data Analysis Module concludes in the office, where the last part of the inspection takes place. Once in field data acquisition phase is completed, in the office the Data Analysis Module allows the inspection team to review the checklists and, supported by the video, to fill missing information or to correct errors before drawing the inspection report.

In this step, the Module puts together data recorded by the front seat operator and the rear seat operator. The user can investigate every single step of the inspection by moving from sheet to sheet and from time to time with the opportunity of reviewing the corresponding video sequence and, if necessary, modify the values of each checklist (Figure 5).

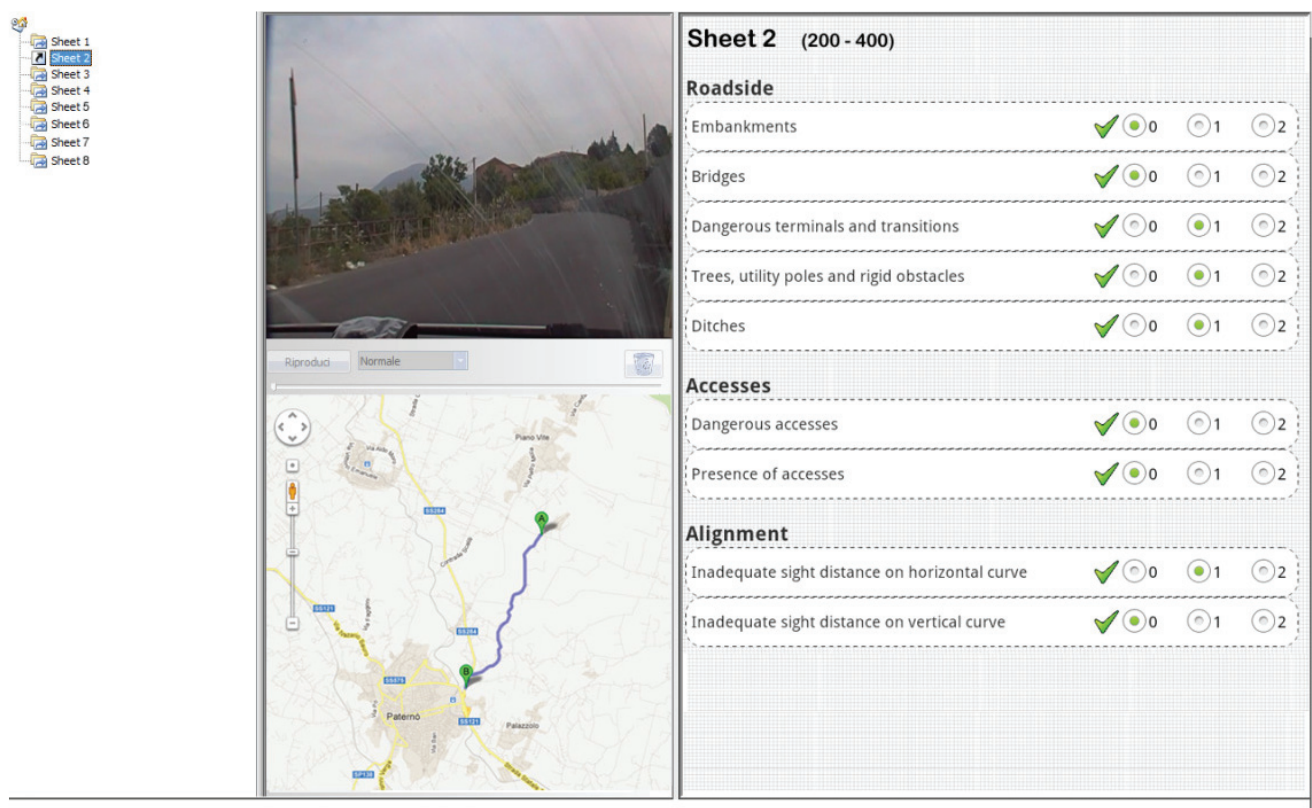

Fig. 5 Data Analysis Module for Office review 
3. The methodologicAl APPROACH to SAFETy EVALUATION OF TWO-LANE RURAL ROADS REFERRING TO SAFETY INSPECTION PROCESS.

One of the most relevant application of the IASP procedure is the development of a risk index. The Risk Index (RI) is a surrogate safety measure, which is defined to supplement crash investigation studies in the safety evaluation of two-lane rural highways by using data from SIs and design consistency models (Cafiso et al. [4]). This measure allows to assess relative safety performance of a rural road segment. RI is a quantitative measure which fills the gap in the use of SIs, which are qualitative in their nature, in the road network safety management. The conceptual formulation of RI is presented below. The reader can refer to the reported references for more detailed information.

\subsection{Formulation of Risk Index (RI)}

The RI is formulated by combining the risk components related to: the exposure of road users to road accident risks EF; the probability of a vehicle being involved in a collision, AFF; the resulting consequences, in case of a crash occurance, ASF.

$$
R I=E F \times A F F \times A S F
$$

\subsubsection{Exposure Factor (EF)}

The exposure factor measures the exposure of road users to road risks and is assessed as follows:

$$
E F=L x A A D T
$$

where:

$-L$ is the length of each unit (in kilometers)

- AADT is average annual daily traffic (in 1.000 vehicles per day).

\subsubsection{Accident Frequency Factor (AFF)}

The accident frequency factor depends on the safety features of the road segment, which are assessed by two analysis methodologies:

- Road Safety Inspection

- Design consistency evaluations and design standard check, which can be a subject of the road safety audit.

The accident frequency factor is expressed by: 


$$
A F F=R S I A F x G D A F
$$

where:

- RSI AF quantifies the presence of safety issues which can be assessed on the basis of road SIs. SIs relate to the main safety issues that can be effectively detected by means of inspections and which are consistently present along two-lane rural roads (Access points, Cross sections, Delineation, Markings, Signs, Pavement, Roadside, Sight distance, Alignment).

- GD AF represents the component related to the design consistency and, more generally, to the horizontal alignment characteristics of the road.

\subsubsection{Accident Severity Factor (ASF)}

The accident severity factor (ASF) is a measure of severity of crashes based on both roadside hazards, identified by SIs, and speed value as the ratio between the 85th percentile of free flow speed (V85) and the posted/design speed (Vbase).

$$
A S F=\left(\frac{V_{85}}{V_{\text {base }}}\right) \times R S I \text { AS } \text { roadside }
$$

\section{Implementation of IASP procedure in Polish Guidelines for SAFEty INSPECTIONS}

As defined in the Polish guidelines (Budzyński et al. [2]), the SIs are carried out using three types of controls: General inspection, Detail inspection and Special inspection during the night and road works. General inspections apply to the national road network, and these are both regular and periodic, performed during the day and inspect the elements located along the road (roadway and roadside) and assessing their impact on road safety in order to allow an efficient and effective action of maintenance and planning of investment work consistent with the existing system of road maintenance in Poland. Detailed inspections are done during the day and consist of a specific control of sections or points with a concentration of accidents (fatalities and serious injuries), which are identified during the risk classification, or as a result of the general inspections. Special inspections at night and during road works are the analysis of the perception of road in the absence of natural light to verify that the road works are carried out properly and protected from the point of view of road safety, including the organization of the traffic in the work area and protection for all road users. Polish guidelines give specific checklists for carrying out these controls, in which issues found along the road are grouped in characteristics of the road, elements of surrounding roads, marking, road 
safety and characteristics of traffic. These checklists are available for all Polish roads, without necessity to create specific checklist for the same class. Each issue found during the inspection should be initially classified as either way a defect to be removed immediately or as a defect which may be fixed in a long term.

The defects should be evaluated and qualified for the four risk categories:

- Class A - small,

- Class B - medium,

- Class C - large,

- Class D - very large.

Class D defects should be corrected as soon as possible. Pending the correction or repairs, these may need temporary protection. Defects in these classes can cause serious consequences such as road accidents, hence the need for a rapid intervention. Defects of Class B and C should be removed as part of maintenance and modernization in function of priority depending on the degree of irregularity, traffic volume and characteristics of the place. Defects of Class A are malfunctions which should be removed as a part of the maintenance. Polish checklists are formed by a high number of issues, that do not allow easy completion during the continuous analysis. SIs are usually carried out manually without support of electronic devices.

This study focus only on the checklists for General inspection than can be filled by two inspectors driving on the road in a vehicle equipped with basic and low cost tools (GPS, video camera and tablets). Two separated checklists are completed: one for the front seat inspector and one for the rear seat inspector, with respectively 33 and 27 points.

For the above reason the goal of the comparison between Polish guidelines and IASP procedures, has been to find a common checklist, synthetic and complete, that could be adopted both in Poland and in Italy. Through use of correspondence codes, it has been observed that many fields in the Polish checklist could be joined in existent Italian fields, while issues that had no correspondence, have been added to the common checklist. The fields relating to problems at intersections are grouped in separate checklists, while issues that are not present in two lane rural roads, have been excluded.

It is possible to see a great deal of similarity with the Italian issues, which has allowed us to create a new checklist basing on the Italian one, which offers more detail but can be completed during a continuous analysis, in a reasonable amount of time for sections of $200 \mathrm{~m}$ of length at a speed of $30 \mathrm{~km} / \mathrm{h}$. The new checklists, reduced in comparison to the original Polish checklist, for front seat inspector (Table 2) and for back seat inspector (Table 3) are shown below.

To comply with the Polish guideline, the original Italian checklist was supplemented with the following new fields: Relating to Vegetation, Road Drainage, Bike Paths, Dirtiness, and Geometrical Design Consistency of Horizontal and Vertical Alignment. Design consistency fields can replace the calculation of the Design Consistency and could allow an assessment of the horizontal alignment during SIs when geometric data 
of horizontal alignment is not available. These factors were considered to have a significant impact on traffic safety on rural road sections.

Table 2

Checklist ITA_PL for General Inspection: Module for Front Seat Inspector

\begin{tabular}{|c|c|c|c|c|c|c|}
\hline & & 0,2 & 0,4 & 0,6 & 0,8 & 1,0 \\
\hline \multicolumn{7}{|c|}{ PART A } \\
\hline \multicolumn{7}{|c|}{ Roadside } \\
\hline I1 & Embankments (P22, P23, P44, P45) & & & & & \\
\hline $\mathrm{I} 2$ & Bridges (P44, P45) & & & & & \\
\hline $\mathrm{I} 3$ & $\begin{array}{l}\text { Dangerous terminals and } \\
\text { transitions (P46) }\end{array}$ & & & & & \\
\hline I4 & $\begin{array}{l}\text { Trees, utility poles } \\
\text { and rigid obstacles (P59, P27) }\end{array}$ & & & & & \\
\hline $\mathrm{I} 5$ & Ditches & & & & & \\
\hline \multicolumn{7}{|c|}{ Alignment } \\
\hline I6 & $\begin{array}{l}\text { Inadequate sight distance on horizontal } \\
\text { curve (P2, P16, P26, P28, P34, P60) }\end{array}$ & & & & & \\
\hline I7 & $\begin{array}{l}\text { Inadequate sight distance on } \\
\text { vertical curve (P2, P16, P26, P28, P } 34, \mathrm{P} 60)\end{array}$ & & & & & \\
\hline I8a & $\begin{array}{l}\text { Geometric design consistency for horizontal } \\
\text { curves (P1) }\end{array}$ & & & & & \\
\hline $\mathrm{I} 8 \mathrm{~b}$ & $\begin{array}{l}\text { Geometric design consistency for horizontal } \\
\text { tangent }(\mathrm{P} 1)\end{array}$ & & & & & \\
\hline I9 & $\begin{array}{l}\text { Geometric design consistency for vertical } \\
\text { alignment (P1) }\end{array}$ & & & & & \\
\hline \multicolumn{7}{|c|}{ PART B } \\
\hline \multicolumn{7}{|c|}{ Accesses } \\
\hline $\mathrm{I} 10$ & Dangerous access (P54) & & & & & \\
\hline I11 & Presence of an access (P55) & & & & & \\
\hline \multicolumn{7}{|c|}{ Vegetation } \\
\hline $\mathrm{I} 12$ & Bad conditions of vegetation (P35) & & & & & \\
\hline I13 & $\begin{array}{l}\text { Vegetation close to the edge of roadway } \\
\text { (P36) }\end{array}$ & & & & & \\
\hline
\end{tabular}


Table 3

Checklist ITA_PL for General Inspection for Back Seat Inspector issues

\begin{tabular}{|c|c|c|c|c|c|c|}
\hline & & 0,2 & 0,4 & 0,6 & 0,8 & 1,0 \\
\hline \multicolumn{7}{|c|}{ PART A } \\
\hline \multicolumn{7}{|c|}{ Cross section } \\
\hline $\mathrm{I} 14$ & Lane width (P9) & & & & & \\
\hline $\mathrm{I} 15$ & Shoulder width (P17, P18, P19) & & & & & \\
\hline \multicolumn{7}{|c|}{ Pavement } \\
\hline I16 & Friction & & & & & \\
\hline $\mathrm{I} 17$ & Unevenness (P24, P27) & & & & & \\
\hline $\mathrm{I} 18$ & Dirtiness (P25) & & & & & \\
\hline \multicolumn{7}{|c|}{ Road drainage } \\
\hline I19 & Lack of runoff water sites (P20) & & & & & \\
\hline $\mathrm{I} 20$ & Incorrect designs (P21) & & & & & \\
\hline \multicolumn{7}{|c|}{ Delineation } \\
\hline $\mathrm{I} 21$ & Chevrons (P64) & & & & & \\
\hline $\mathrm{I} 22$ & $\begin{array}{l}\text { Guideposts and barrier } \\
\text { reflectors (P64) }\end{array}$ & & & & & \\
\hline \multicolumn{7}{|c|}{ PART B } \\
\hline \multicolumn{7}{|l|}{ Signs } \\
\hline $\mathrm{I} 23$ & $\begin{array}{l}\text { Warning signs, regulation signs (P37,P38, } \\
\text { P39, P40,P47, P48, P49, P63) }\end{array}$ & & & & & \\
\hline \multicolumn{7}{|c|}{ Markings } \\
\hline $\mathrm{I} 24$ & Edge lines (P42, P43, P63) & & & & & \\
\hline $\mathrm{I} 25$ & Center lines (P42, P43, P63) & & & & & \\
\hline \multicolumn{7}{|c|}{ Bike paths } \\
\hline I26 & Incorrect geometrical parameters (P14) & & & & & \\
\hline $\mathrm{I} 27$ & Lack of bike paths (P15) & & & & & \\
\hline
\end{tabular}




\section{Correlation between IASP and Polish procedures Risk category}

\subsection{Safety inspection on Regional roads in Poland}

One of the aims of the paper was to compare methods and their unification in terms of ranking of traffic safety problems. For this purpose, on the regional roads in Malopolska SIs were carried out basing on both the IASP method and Polish method, using the recommended low cost equipment.

These inspections were conducted on 7 sections of the regional roads in Malopolska with a length of $184.48 \mathrm{~km}$ (out of a total number of 39 roads with total length of $1,372.5 \mathrm{~km}$ ), of which $98.052 \mathrm{~km}$ were rural sections and therefore were included in the study. Other sections, passing through built-up areas, with a length of $86,428 \mathrm{~m}$ were not included in the study. This affected how the inspection was conducted and also the analysis of results. SIs have been paused and re-started when the built-up area ended. Such approach leads to a fragmented safety analysis and it was not continuous along the examined road.

In order to obtain a significant sample of data have been subjected to SIs about 100 $\mathrm{km}$ of road. The choice has been based on value assumed by Accident Rate parameter in order to identify those sections including high risk sites of the network.

Accident Rate was calculated for a homogeneous section in function of the traffic volume. The principal data required in order to draw up a classification of the section, is represented by the length of a homogeneous road section, accident data from previous years (including number of fatalities and injured) and average traffic volumes.

In general, for the individuation of homogeneous road sections several elements have been taken into account, such as:

- type of terrain (flat or mountainous terrain)

- functional class of the road

- geometric characteristics of road axis

- Annual Average Daily Traffic AADT

For each homogenous section, Accident Rate has been calculated with the formula:

$$
\text { A.R. } \left.=\frac{\text { number of accident } \times 10^{6}}{\text { average } A A D T \times L \times 7 \times 365} \quad \text { [acc. } / 1 \mathrm{mln} \text { veh. } \mathrm{km}\right]
$$

in which the number of accidents and average value of traffic volume have been considered; these data was provided by the Voivodeship Road Administration, from the seven-year period 2007 and 2013.

The procedure used to identify the threshold values of A.R. has been based on a quantitative analysis of total length of the analyzed section; it has been observed that for higher values of A.R, such as 0.3 (for 42 reference sections of the total length of $19.605 \mathrm{~km}$ of length), while for value of A.R. equal to 0.2 the number of reference 
sections was 116 for a total of $144.095 \mathrm{~km}$. The number of all reference sections were sufficient sample size for conducted analysis.

It is clear that the inspection has been extended to all roads which have high risk sections, because SIs are by definition carried out continuously along the road.

A list of selected roads which presented a high number of critical sections located in a flat environment, is shown in the Table 4.

Table 4

Roads selected for Safety Inspections

\begin{tabular}{|c|c|c|c|}
\hline No. of road & Class of road & From...to... & Length of road \\
\hline 774 & $\mathrm{G}$ & Zabierzów - Kryspinów & $8.4 \mathrm{~km}$ \\
\hline 780 & $\mathrm{G}$ & Kraków - Libiąż & $38.77 \mathrm{~km}$ \\
\hline 791 & $\mathrm{G}$ & Wanaty - Trzebinia & $35.4 \mathrm{~km}$ \\
\hline 794 & $\mathrm{G}$ & Wolbrom - Skala & $18.10 \mathrm{~km}$ \\
\hline 964 & $\mathrm{G}$ & Ispina - Biskupice Radł. & $35.40 \mathrm{~km}$ \\
\hline 966 & $\mathrm{G}$ & Wieliczka - Gdów & $13.31 \mathrm{~km}$ \\
\hline 967 & $\mathrm{G}$ & Myślenice - Łapczyca & $35.1 \mathrm{~km}$ \\
\hline \multicolumn{2}{r}{} & & $184.48 \mathrm{~km}$ \\
\hline
\end{tabular}

\subsection{Correlation between IASP and Polish Severity score}

In the checklist fields it is possible to give a score for each issues:0, 1, 2 representing the severity of the problem found along the road (0: no problem, 1: medium level, 2: high level problem), as explained in the IASP manual (Cafiso et al. [3]). In the Polish guideline when a defect is identified, the severity has to be classified into four categories $(\mathrm{A}, \mathrm{B}, \mathrm{C}, \mathrm{D})$.

The IASP score and the Polish risk category can be compared in terms of equivalent safety risk. For this purpose, the Risk Index can be used to evaluate the range of the IASP score for each safety issue included in the check list.

Calculations of RI were conducted basing on the method previously introduced and presented in detail elsewhere (Cafiso et al. [4]). The following base values were assumed in the further calculations:

- length of section $200 \mathrm{~m}$;

- $\mathrm{AADT}=10,000$ vehicles/day;

- $\mathrm{V}_{\text {base }}=90 \mathrm{~km} / \mathrm{h}$, general speed limit,

- $\mathrm{V}_{85 \%}=100 \mathrm{~km} / \mathrm{h}$, from measurements carried out on Polish regional roads;

- one inspection unit.

For the proportion of accident typs we have used the data provided by the Voivodeship Road Administration, collected over seven years between 2007 and 2013 (for the Małopolska Region) (Table 5). 
Table 5

Proportion of accident types

\begin{tabular}{|c|c|}
\hline Type of accidents & $\boldsymbol{P j}(\%)$ \\
\hline Head on & 22.2 \\
\hline Side on & 27.9 \\
\hline Rear end & 10.4 \\
\hline Run off the road & 27.8 \\
\hline Others & 11.7 \\
\hline All & 100.00 \\
\hline
\end{tabular}

In proportion of accident types, those relating to hitting pedestrian have been excluded, because conflicts between drivers and pedestrian are not considered in the present form of the checklist for two lane rural roads. For each safety issue $j$ the ratio of $R I_{j}$ and $R I_{\max }$ has been calculated, as following:

$$
\frac{R I_{j}}{R I_{\max }} 100
$$

where:

- $R I_{j}$ is Risk Index value for issue $j$ for different severity scores $(0,1,2)$;

- $R I_{\max }$ is maximum value of Risk Index for all of the safety categories.

Ranges of variation of the RI have been identified as a function of the values of this ratio, which allow to define the correlation between the IASP scores and the Polish evaluations (Table 6).

Table 6

Score Correlation

\begin{tabular}{|c|c|c|c|c|c|}
\hline Polish evaluations & - & $\mathrm{A}$ & $\mathrm{B}$ & $\mathrm{C}$ & $\mathrm{D}$ \\
\hline$\frac{\boldsymbol{R} \boldsymbol{I}_{\boldsymbol{j}}}{\boldsymbol{R} \boldsymbol{I}_{\max }}$ & $\leq 60$ & $>60-\leq 70$ & $>70-\leq 80$ & $>80-\leq 90$ & $>90-\leq 100$ \\
\hline
\end{tabular}

Based on the ratio from Table 6 it has been possible to identify the risk category for each type of problem, as shown in the following Table 7 and Table 8.

Based on SIs on regional roads in Poland and taking into account comparison of IASP severity score and Polish risk categories, a percentage shares of sections with their respective issue classes, have been identified (Figure 6). In can be concluded from Fig. 6 that the highest risks on the Małopolska regional roads is caused by: 
- excessive number of access points - such a problem is observed at ca. $84.4 \%$ of rural roads (risk categories $\mathrm{C}$ and $\mathrm{D}$ ),

- high embankments with insufficient protection, which are a problem at $35.4 \%$ of regional roads

- sections with unprotected bridge objects adjacent to the road - category D risk, which requires immediate action - are observed at $1.1 \%$ of the inspected roads

- the most common problem, observed at $95.3 \%$ of the roads, is insufficient shoulder width. Category B of this problem indicates there is no need for immediate action to remove this threat.

Table 7

Comparison of IASP severity level and Polish risk categories for Front Seat Inspector issues

\begin{tabular}{|c|c|c|}
\hline Safety Issue & $\begin{array}{l}\text { IASP severity } \\
\text { score }\end{array}$ & $\begin{array}{c}\text { Polish risk } \\
\text { category }\end{array}$ \\
\hline \multicolumn{3}{|l|}{ Roadside } \\
\hline \multirow{3}{*}{ Embankments } & 0 & - \\
\hline & 1 & $\mathrm{~B}$ \\
\hline & 2 & $\mathrm{C}$ \\
\hline \multirow{3}{*}{ Bridges } & 0 & - \\
\hline & 1 & $\mathrm{~B}$ \\
\hline & 2 & $\mathrm{D}$ \\
\hline \multirow{3}{*}{ Dangerous terminals and transitions } & 0 & - \\
\hline & 1 & $\mathrm{~A}$ \\
\hline & 2 & $\mathrm{~B}$ \\
\hline \multirow{3}{*}{ Trees, utility poles and rigid obstacles } & 0 & - \\
\hline & 1 & $\mathrm{~A}$ \\
\hline & 2 & $\mathrm{~B}$ \\
\hline \multirow{3}{*}{ Ditches } & 0 & - \\
\hline & 1 & $\mathrm{~A}$ \\
\hline & 2 & A \\
\hline \multicolumn{3}{|l|}{ Alignment } \\
\hline \multirow{3}{*}{ Inadequate sight distance on horizontal curve } & 0 & - \\
\hline & 1 & A \\
\hline & 2 & $\mathrm{~B}$ \\
\hline \multirow{3}{*}{ Inadequate sight distance on vertical curve } & 0 & - \\
\hline & 1 & A \\
\hline & 2 & $\mathrm{~B}$ \\
\hline \multicolumn{3}{|l|}{ Accesses } \\
\hline \multirow{3}{*}{ Dangerous accesses } & 0 & - \\
\hline & 1 & $\mathrm{C}$ \\
\hline & 2 & $\mathrm{D}$ \\
\hline \multirow{3}{*}{ Presence of accesses } & 0 & - \\
\hline & 1 & $\mathrm{C}$ \\
\hline & 2 & $\mathrm{D}$ \\
\hline
\end{tabular}


Table 8

Comparison of IASP severity score and Polish risk categories: Module for Back Seat Inspector

\begin{tabular}{|c|c|c|}
\hline Safety Issue & $\begin{array}{l}\text { IASP severity } \\
\text { score }\end{array}$ & $\begin{array}{c}\text { Polish risk } \\
\text { category }\end{array}$ \\
\hline \multicolumn{3}{|l|}{ Cross section } \\
\hline \multirow{3}{*}{ Lane width } & 0 & - \\
\hline & 1 & $\mathrm{~A}$ \\
\hline & 2 & $\mathrm{~B}$ \\
\hline \multirow{3}{*}{ Shoulder width } & 0 & - \\
\hline & 1 & $\mathrm{~A}$ \\
\hline & 2 & $\mathrm{~B}$ \\
\hline \multicolumn{3}{|l|}{ Pavement } \\
\hline \multirow{3}{*}{ Friction } & 0 & - \\
\hline & 1 & $\mathrm{~A}$ \\
\hline & 2 & $\mathrm{~A}$ \\
\hline \multirow{3}{*}{ Unevenness } & 0 & - \\
\hline & 1 & $\mathrm{~A}$ \\
\hline & 2 & $\mathrm{~A}$ \\
\hline \multicolumn{3}{|l|}{ Delineation } \\
\hline \multirow{3}{*}{ Chevrons } & 0 & - \\
\hline & 1 & $\mathrm{~A}$ \\
\hline & 2 & $\mathrm{~A}$ \\
\hline \multirow{3}{*}{ Guideposts and barrier reflectors } & 0 & - \\
\hline & 1 & $\mathrm{~A}$ \\
\hline & 2 & A \\
\hline \multicolumn{3}{|l|}{ Markings } \\
\hline \multirow{3}{*}{ Edge lines } & 0 & - \\
\hline & 1 & A \\
\hline & 2 & $\mathrm{~A}$ \\
\hline \multirow{3}{*}{ Center lines } & 0 & - \\
\hline & 1 & A \\
\hline & 2 & A \\
\hline \multicolumn{3}{|l|}{ Signs } \\
\hline \multirow{3}{*}{ Warning signs, regulation signs } & 0 & - \\
\hline & 1 & A \\
\hline & 2 & $\mathrm{~B}$ \\
\hline
\end{tabular}




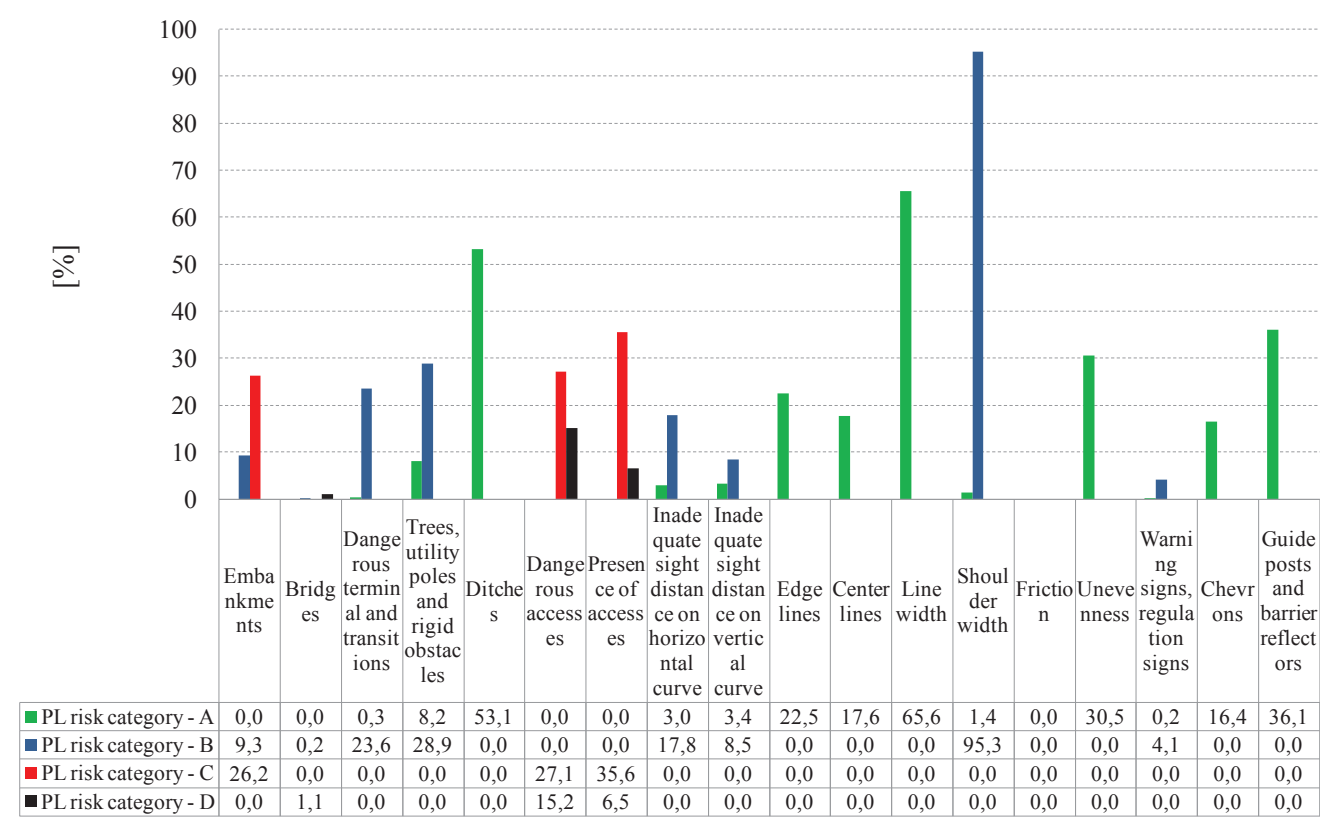

Fig. 6. Characteristics of problems basing on the conducted road inspection.

\section{Conclusions}

Basing on the conducted analyses and comparisons of the road safety inspection performed on regional roads in Poland, it can be concluded that:

- The results are promising for the introduction of adopted Italian procedure and tools for the road safety management on two lane rural roads in Poland. The procedure can improve effectiveness of the SIs process and its usability. It is possible to apply the IASP method and equipment to carry out SIs in Poland, which would comply with the Polish guidelines.

- To ensure efficiency of the SIs, it is necessary to limit the number of issues in Polish checklist, which should be described during the inspection. And for this purpose checklist developed on the basis of the two methods could be considered.

- As the next step in the research, the model of Risk Index developed for the Italian roads will be applied to the Polish roads using data of the inspected sections. Also the correlation of the RI with the actual crash frequency will be tested. When completed, this procedure will make it possible to identify and prioritize the intervention strategies that produce the greatest safety benefits while being compatible with the available annual budget. 
- It is necessary to develop a procedure of risk assessment for rural roads passing through built-up areas, due to their large share in the road network and high impact on road safety (Gaca and Kieć [9]).

- Some of the threats caused by the road infrastructure are only characteristic for the given region; this should be taken into account when training new inspectors and creating new checklists.

\section{REFERENCES}

1. Directive 2008/96/EC of the European Parliament and of the Council of 19 November 2008 on road infrastructure safety management http://eur-lex.europa.eu/LexUriServ/LexUriServ. do?uri=CELEX:32008L0096:EN:NOT Accessed July 15, 2013

2. Budzyński, M., Gaca, S., Jamroz, K., Michalski, L., Instruction of safe controll for road traffic (in Polish), Politechnika Gdańska, 2013

3. S. Cafiso, G. La Cava, A. Montella, G. Pappalardo, Manuale per le Ispezioni di Sicurezza delle Strade Extraurbane Secondarie e Locali - Operative Procedure for Safety Inspections on Two - Lane Rural Roads Project TREN - 03 - ST - S07.31286 - Aracne Editrice. ISBN 978-88-548-1429-5. Gennaio 2008.

4. S. Cafiso, G. La Cava, A. Montella, Safety Index for Evaluation of Two Rural Highways, Transportation Research Record: Journal of the Transportation Research Board, issue number 2019, 136-145, 2007

5. European Commission, Transport, Road Safety. Road Safety evolution in the EU http://ec.europa.eu/ transport/road_safety/specialist/statistics/index_en.htm Accessed November 14, 2014

6. Ministero delle Infrastrutture e dei Trasporti. D.M. 5/11/2001 Norme Funzionali E Geometriche Per La Costruzione Delle Strade, 2001

7. Cafiso, S., La Cava, G. Montella, A. \& Pappalardo, G., A Procedure to Improve Safety Inspections Effectiveness and Reliability on Rural Two- Lane Highways. The Baltic Journal of Road and Bridge Engineering, Vilnius: Technika, Vol I, No 3, 143-150, 2006

8. Cafiso, S., Di Graziano, A., Giudice, O., Pappalardo, G., Tools for Road Inspection and Safety Management. 3rd International Conference on Transportation Infrastructure, Pisa, April 22-25, 2014.

9. Gaca S., Kieć M., Quantification of impacts of road accessibility and selected factors of road surroundings development on road traffic safety. Transportation Research Board 91st Annual Meeting 2012, Washington, 2012, Paper \#12-3282 
